\title{
The Centrality of Chemistry
}

\author{
Thomas F George ${ }^{1 *}$, Guoping Zhang ${ }^{2}$ and Renat R Letfullin ${ }^{3}$ \\ ${ }^{1}$ University of Missouri-St Louis, USA \\ ${ }^{2}$ Indiana State University, USA
}

${ }^{3}$ Rose-Hulman Institute of Technology, USA

*Corresponding author: Thomas F George, University of Missouri-St Louis, USA

Submission: 毕 February 11, 2019; Published: 眥 February 15, 2019

\section{Editorial}

We applaud Crimson Publishers for launching the new online journal called Annals of Chemical Science Research. It can be argued that chemistry represents the most commonly shared branch of science and engineering among the various disciplines, including physics, biology, materials, spectroscopy and lasers/ optics - hence its descriptor of centrality. To fully understand and appreciate any field of science (pure and applied), being grounded in the fundamentals of chemistry is essential. This is of course why varying levels of chemistry courses are required by students majoring in any area of science and many areas of engineering.

Chemistry is often the glue that connects various fields in an interdisciplinary manner and gaining an understanding of the principles of chemistry helps with learning and defining principles in other areas. An example is the role of energy, where descriptions of spectroscopic processes in molecules and chemicals are similar to those in solid-state physics but associated with different energy regimes: transition energies in chemistry typically fall on the electron volt $(\mathrm{eV})$ scale, whereas they fall on the meV scale in solid-state physics. What are called the highest-occupied and lowest-unoccupied molecular orbitals in a molecule corresponds, respectively, to valence and conduction bands in solid-state physics, with the Fermi level occurring in both cases. Analogously, the transitions occur on different time scales, where the time decreases as the transition energy increases. An interesting and fun book to read along these lines was published three decades ago by 1981 Chemistry Nobel Laureate Roald Hoffmann [1], where he draws analogies between surface physics and chemistry.

Let us touch on two areas of science where chemistry provides the foundation: ultrafast laser processes and nanomedicine. Regarding the former, one must realize that the creation of laser pulses is indeed a coherent chemical process. And then the interaction of such pulses with materials is directly related to chemistry. An example is provided by our recent study of laser- induced ultrafast transport and demagnetization, where we compare the demagnetization in different chemical systems. This work combines chemistry with laser optics and surface/solid-state physics.

The second area, nanomedicine, represents a relatively new branch of both pure and applied science. The word "nano" refers to species whose size is on the order of a nanometer, which is essentially in the realm of chemical/molecular/cluster physics. Chemical reactions combined with nanoparticles subject to laser irradiation can be used to target cancer cells in a very selective manner to ultimately eliminate traditional chemotherapy kills healthy cells as well. A promising element in this regard is gold used at the nanoscale size in the form of nanoparticles, nanorods and nanoclusters. Research in this area requires the tools of chemical kinetics and nanotechnology, as well as laser physics. We have summarized a number of ideas and advances in nanomedicine in a pedagogical book published in 2016 [2,3].

As chemistry interfaces with other fields of science, it is clear that its outreach is broad, encompassing a wide variety of topics. The articles appearing in this first issue of Annals of Chemical Science Research testify to this, covering topics like: (1) nanochemistry as a toolbox for nanoparticle-based diagnosis and therapy, (2) the moving force of chemical reactions, and (3) liquefaction of lignocelluloses as a promising alternative to petrochemicals. This journal is off to a great start!

\section{References}

1. Hoffmann R (1988) Solids and surfaces: A chemist's view of bonding in extended structures. Wiley-VCH, Germany.

2. Zhang GP, Bai, YH, Jenkins T, George TF (2018) laser-induced ultrafast transport and demagnetization at the earliest time: first-principles and real-time investigation. J Phys Condens Matter 30(46): 465801.

3. Letfullin RR, George TF (2016) Computational nanomedicine and nanotechnology: lectures with computer practicums. Springer International Publishing, Cham, Switzerland. 
Creative Commons Attribution 4.0 International License

For possible submissions Click Here Submit Article

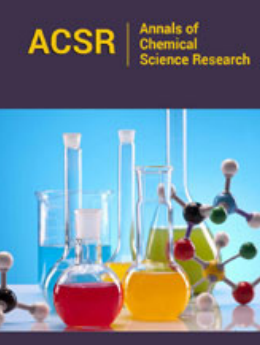

\section{Annals of Chemical Science Research}

\section{Benefits of Publishing with us}

- High-level peer review and editorial services

- Freely accessible online immediately upon publication

- Authors retain the copyright to their work

- Licensing it under a Creative Commons license

- Visibility through different online platforms 